\title{
The need for speed: observational study of physician driving behaviors
}

\author{
André Zimerman, ${ }^{1}$ Christopher Worsham, ${ }^{1,2,3}$ Jaemin Woo, ${ }^{1}$ Anupam B Jena ${ }^{1,2,4}$
}

${ }^{1}$ Department of Health Care

Policy, Harvard Medical School,

Boston, MA 02115, USA

${ }^{2}$ Department of Medicine,

Massachusetts General

Hospital, Boston, MA, USA

${ }^{3}$ Division of Pulmonary

and Critical Care Medicine,

Massachusetts General

Hospital, Boston, MA, USA

${ }^{4}$ National Bureau of Economic

Research, Cambridge, MA, USA

Correspondence to: A B Jena

jena@hcp.med.harvard.edu

(@anupambjena on Twitter

ORCID 0000-0002-9734-5122)

Additional material is published online only. To view please visit

the journal online.

Cite this as: $B M J$ 2019;367:16354 http://dx.doi.org/10.1136/bmj.16354

Accepted: 14 October 2019

\section{ABSTRACT}

OBJECTIVE

To determine whether fast driving, luxury car ownership, and leniency by police officers differ across medical specialties.

DESIGN

Observational study.

SETTING

Florida, USA.

\section{PARTICIPANTS}

5372 physicians and a sample of 19639 non-

physicians issued a ticket for speeding during 2004-17.

\section{MAIN OUTCOME MEASURES}

Observed rates of extreme speeding (defined as driving $>20 \mathrm{mph}$ above the speed limit), luxury car ownership, and leniency of the speeding ticket by police officers, by physician specialty, after adjustment for age and sex.

\section{RESULTS}

The sample included 5372 physicians who received 14560 speeding tickets. The proportion of drivers who were reported driving at speeds greater than 20 mph was similar between physicians and a sample of 19639 non-physicians who received a ticket for speeding ( $26.4 \% \vee 26.8 \%$ of tickets, respectively). Among physicians who received a ticket, psychiatrists were most likely to be fined for extreme speeding (adjusted odds ratio of psychiatry compared with baseline specialty of anesthesia 1.51, 95\% confidence interval 1.07 to 2.14). Among drivers who received a ticket, luxury car ownership was most common among cardiologists (adjusted proportion of ticketed cardiologists who owned a luxury car

\section{WHAT IS ALREADY KNOWN ON THIS TOPIC}

Many people believe medical specialty choices are associated with certain personalities

Driving behaviors, such as fast driving, luxury car ownership, and leniency by police officers have also been linked to personal traits in the general population No prior study has examined driving behaviors in physicians

\section{WHAT THIS STUDY ADDS}

In an analysis of Florida traffic violation data linked to physician characteristics, extreme speeding was most common among psychiatrists but otherwise similar across specialties

Among physicians who received a ticket for speeding, cardiologists were more likely to be driving luxury cars, and emergency physicians, family physicians, pediatricians, general surgeons, and psychiatrists were less likely

Leniency by policy officers towards physicians pulled over for speeding was common, but did not vary by specialty, and was similar between physicians and non-physicians

$40.9 \%, 95 \%$ confidence interval $35.9 \%$ to $45.9 \%$ ) and least common among physicians in emergency medicine, family practice, pediatrics, general surgery, and psychiatry (eg, adjusted proportion of luxury car ownership among family practice physicians $20.6 \%$, $95 \%$ confidence interval $18.2 \%$ to $23.0 \%$ ). Speed discounting, a marker of leniency by police officers in which ticketed speed is recorded at just below the threshold at which a larger fine would otherwise be imposed, was common, but rates did not differ by specialty and did not differ between physicians and a sample of non-physicians.

\section{CONCLUSIONS}

Rates of extreme speeding were highest among psychiatrists who received a ticket, whereas cardiologists were the most likely to be driving a luxury car when ticketed. Leniency by police officers was similar across specialties and between physicians and non-physicians.

\section{Introduction}

An estimated 7.85 million Americans were stopped by police for speeding in 2015. ${ }^{1}$ Although physicians were among this group, the driving behaviors of physicians are unknown, including the specialties most strongly associated with faster driving, the make of cars driven by these physicians, and whether some specialties are treated more leniently by police officers than others. In the general population, speeding violations are associated with certain characteristics of drivers such as sex, occupation, and risk taking personality traits. ${ }^{23}$ Leniency by police officers toward drivers pulled over for speeding has also been shown to be influenced by personal factors such as race, age, sex, and even whether a driver shares the same first name as the police officer. $^{4-6}$

Using data on speeding tickets in Florida from 2004 to 2017 , linked to publicly available data on physician characteristics, we analyzed which specialties had physicians with a greater need for speed, which specialties commonly owned luxury cars, and whether physicians in certain specialties received more lenient treatment by law enforcement when pulled over for speeding.

\section{Methods}

\section{Data sources}

Our study obtained information from two primary databases. The first was publicly available ticket level data for all traffic citations issued by the highway patrol in Florida during 2004-17. The database, which has been used in prior analyses, ${ }^{45}$ included driver name, age, sex, driver license number, driving speed, location of the violation, and make of car. The second database 
was the National Plan and Provider Enumeration System National Provider Identifier Registry, which included information on specialty, age, and sex for all registered physicians in the United States. Physicians were identified in the ticketing database by matching on first name, last name, state of residence, and age. To ensure that physicians with common first and last names were not incorrectly designated as being ticketed more often than was the case, we excluded instances in which a name in the physician database matched (based on first or last name and age) to more than one driver's license number. We also excluded tickets issued to physicians aged less than 30 years as these matches might reflect tickets issued to those who later became physicians. A sample of tickets for non-physicians aged 30 years or more was included for comparison.

\section{Definitions}

We studied three outcomes related to physician driving. First, we identified instances of extreme speeding, defined as being ticketed for driving at least $20 \mathrm{mph}$ above the speed limit. This analysis was conducted to identify those specialties with the greatest "need for speed." Second, we analyzed rates of driving a luxury car among drivers who received speeding tickets. This analysis was done to determine which specialists drive the fanciest cars. We defined the following makes as luxury cars: Acura, Audi, BMW, Cadillac, Ferrari, Infiniti, Jaguar, Land Rover, Lexus, Lotus, Maserati, Mercedes, Porsche, Tesla, and Volvo. Third, a common way police officers are lenient to some drivers is to cite lower speeds for those drivers so as to impose a smaller fine. ${ }^{4-6}$ We studied whether this phenomenon, known as speed discounting, was more common among those specialists who interact with police officers in their work and therefore may receive preferential treatment, such as doctors specializing in emergency medicine who treat injured police officers or members of the public brought to the emergency department by the officers. We considered tickets to have been discounted when speeds were cited at exactly $9 \mathrm{mph}$ above the speed limit, given that in Florida steeply greater fines accrue when the ticketed speed is more than 10 mph over the limit. ${ }^{6}$

\section{Statistical analysis}

We estimated separate ticket level multivariable logistic regression models of whether a ticket involved extreme speeding, driving a luxury car, and being subject to ticket discounting, as a function of medical specialty, physician age, and sex. These last two covariates were included since differences in speeding between specialties could be due to factors such as age and sex that are correlated with specialty choice. Anesthesiology was used as the reference group. We presented adjusted rates of each outcome by specialty using marginal standardization (also known as predictive margins or margins of responses). Statistical analyses were conducted in R Software.

\section{Patient and public involvement}

No patients were involved in setting the research question or the outcome measures, nor were they involved in developing plans for the design or implementation of the study. No patients were asked to advise on interpretation or writing up of results. There are no plans to disseminate the results of the research to study participants or the relevant patient community.

\section{Results}

The study sample comprised 5372 physicians issued 14560 tickets and a sample of 19639 non-physicians issued 63382 tickets between 2004 and 2017 (see supplementary fig 1). The mean age among the physicians was 48.9 years (median 48 , interquartile range 40-56). Female drivers accounted for $16.9 \%$ (2465) of ticketed physicians.

Table 1 displays the distribution of tickets and speeding information by medical specialty. Internal medicine (12.3\% of all tickets) and family practice (12.0\%) accounted for the most tickets overall. Speed was recorded for $37.6 \%(n=5469)$ of tickets. Overall mean speed above the limit was $15.8 \mathrm{mph}$. On average, $26.4 \%$ of the speeding tickets issued to physicians and $26.8 \%$ issued to non-physicians involved extreme speeding, defined as driving $20 \mathrm{mph}$ or more above the speed limit ( $\mathrm{P}=0.67$ for difference). The need for speed record belonged to a general internist, who drove at $70 \mathrm{mph}$ above the limit. Although extreme speeding was common across specialties, rates were similar in magnitude and the only specialty statistically significantly associated with extreme speeding compared with the baseline specialty of anesthesiology was psychiatry (fig 1; supplementary fig 2 and table 1). Male sex and younger age were also statistically significantly associated with extreme speeding.

In the database, car make was documented for $63.8 \%(n=9291)$ of tickets assigned to physicians. Of these, $31.4 \%(n=2915)$ were luxury cars compared with $11.8 \%$ (4237/37 569) for tickets issued to nonphysicians $(\mathrm{P}<0.001)$. Figure 2 shows the distribution of speeding tickets by specialty when driving a luxury car. Overall, the specialists who accounted for the most luxury cars driven were general internists (14.3\%), internal medicine subspecialists (11.5\%), and anesthesiologists (8.4\%). In an adjusted analysis, the percentage of luxury cars varied by specialty, from $20.6 \%$ for family practice to $40.9 \%$ for cardiology (fig 3; supplementary fig 3). Compared with anesthesiologists, cardiologists were significantly more likely to drive a luxury car (adjusted odds ratio 1.41, 95\% confidence interval 1.09 to 1.82), whereas physicians in emergency medicine, family practice, pediatrics, general surgery, and psychiatry were less likely (supplementary table 2).

Among 5469 speeding tickets with a speed registered, 97.2\% $(n=5315)$ were at least $9 \mathrm{mph}$ above the limit. Of these, $26.2 \%$ of the tickets issued to physicians and $26.3 \%$ issued to non-physicians 


\begin{tabular}{|c|c|c|c|}
\hline Medical specialty & $\begin{array}{l}\text { No of tickets } \\
\text { (\% of total) }\end{array}$ & $\begin{array}{l}\text { Average speed } \\
\text { above limit (mph) }\end{array}$ & $\begin{array}{l}\text { Extreme speeding* } \\
\text { (\% within specialty) }\end{array}$ \\
\hline All specialties & $14560(100)$ & 15.8 & $1445(26.4)$ \\
\hline Anesthesiology & $1207(8.3)$ & 15.7 & $109 / 441(24.7)$ \\
\hline Cardiology & $627(4.3)$ & 16.3 & $69 / 237(29.1)$ \\
\hline Emergency medicine & $736(5.1)$ & 16.2 & $85 / 300(28.3)$ \\
\hline Family medicine & $1749(12.0)$ & 15.4 & $146 / 602(24.3)$ \\
\hline General surgery & $536(3.7)$ & 15.8 & $53 / 177(29.9)$ \\
\hline Internal medicine subspecialty & $1404(9.6)$ & 16.0 & $157 / 575(27.3)$ \\
\hline General internal medicine & $1787(12.3)$ & 16.4 & $205 / 691(29.7)$ \\
\hline Obstetrics and gynecology & $661(4.5)$ & 15.4 & $61 / 250(24.4)$ \\
\hline Orthopedic medicine & $574(3.9)$ & 16.8 & $66 / 232(28.4)$ \\
\hline Other & $1873(12.9)$ & 15.6 & $182 / 702(25.9)$ \\
\hline Pediatrics & $1025(7.0)$ & 15.2 & $79 / 352(22.4)$ \\
\hline Psychiatry & $657(4.5)$ & 16.5 & $78 / 250(31.2)$ \\
\hline Radiology & $665(4.6)$ & 15.5 & $61 / 250(24.4)$ \\
\hline Surgical subspecialty & $1059(7.3)$ & 15.4 & $94 / 410(22.9)$ \\
\hline
\end{tabular}

were recorded as exactly $9 \mathrm{mph}$ above the limit $(\mathrm{P}=0.95)$. Overall, physicians were at least 2.9 times more likely to be recorded as driving $9 \mathrm{mph}(1392$ tickets) above the speed limit than any speed $10 \mathrm{mph}$ or more (3923 tickets) (supplementary fig 4). Older age and female sex, but no medical specialties, were independently associated with leniency in receiving a ticket for speeding (fig 4; supplementary fig 5 and table 3).

\section{Discussion}

In an analysis of nearly 15000 speeding tickets issued to physicians in Florida between 2004 and 2017, we found broadly similar speeding patterns and leniency by police officers between medical specialties but prominently different rates of luxury car ownership. Among physicians who were given a ticket, extreme speeding was common-about one quarter of tickets involved driving more than $20 \mathrm{mph}$ above the speed limit. Rates of extreme speeding and leniency by policy officers were also similar between physicians and non-physicians. We hypothesized that rates of extreme speeding would vary across specialties, owing to underlying personalities and specific professional requirements. For example, physicians in some specialties may exhibit thrill seeking behavior, whereas physicians in certain specialties such as obstetrics and surgery might be called from home to attend medical emergencies. Although the average speed over the limit varied little across specialties, psychiatrists who were ticketed were statistically significantly more likely to drive at extreme speeds, a behavior that based on our prior research cannot be explained by wanting to get to the golf course in a hurry. ${ }^{7}$ Notably, only $18.5 \%$ of tickets were assigned to women, despite women comprising one third of physicians in the US; among these speeding tickets, women also had lower rates of extreme speeding.

Luxury cars were common among physicians who received speeding tickets, and luxury car ownership was highest among ticketed cardiologists. To our knowledge, the only prior study of luxury car ownership by physicians was conducted in the United Kingdom and studied associations between phase of physician training and ownership of newer, high performance sports cars with "charisma," finding that senior house officers were more likely than less advanced house officers or more senior physicians to own a car with high charisma scores. ${ }^{8}$ The widely held belief that luxury car owners are more likely to receive

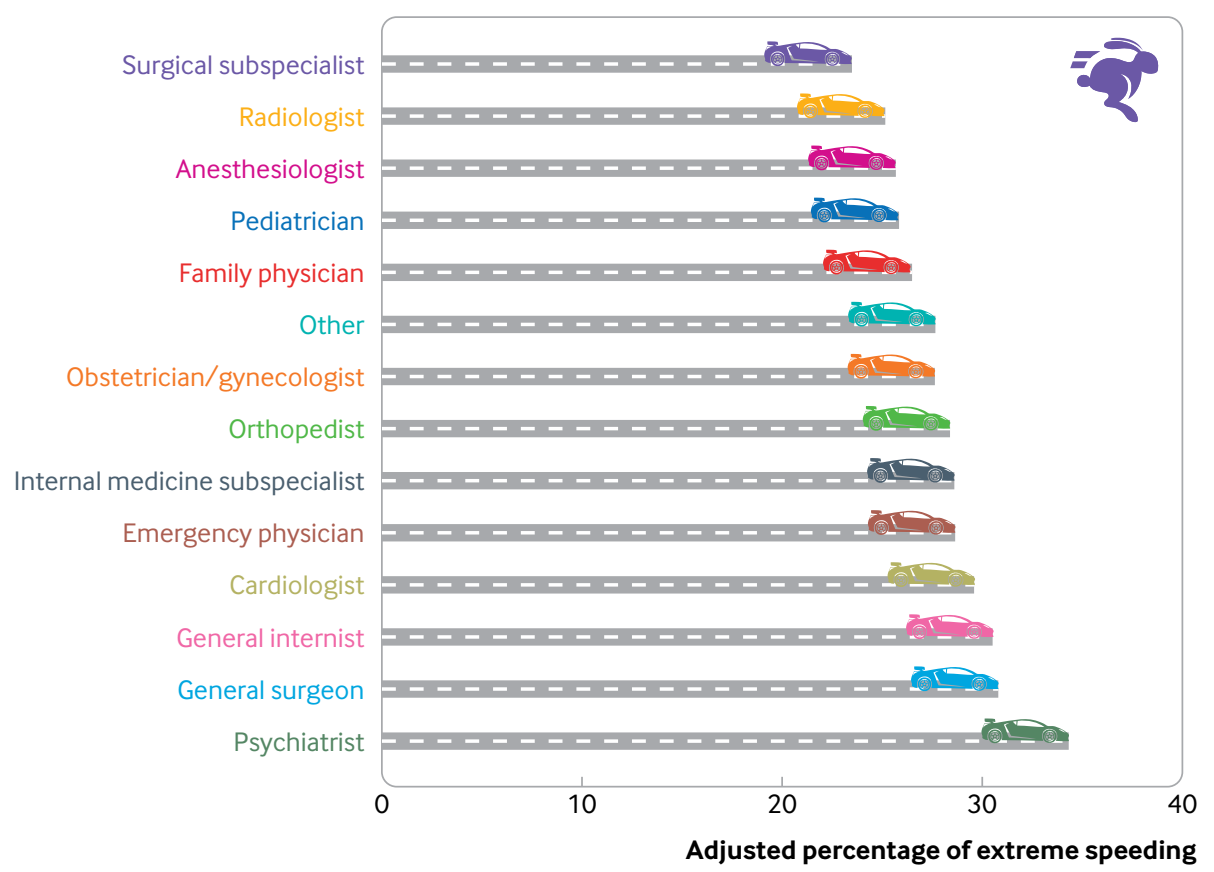

Fig 1 | Adjusted percentage of tickets involving extreme speeding, by physician specialty. Extreme speeding was defined as driving at least $20 \mathrm{mph}$ above the speed limit. Percentages were adjusted for age and sex 


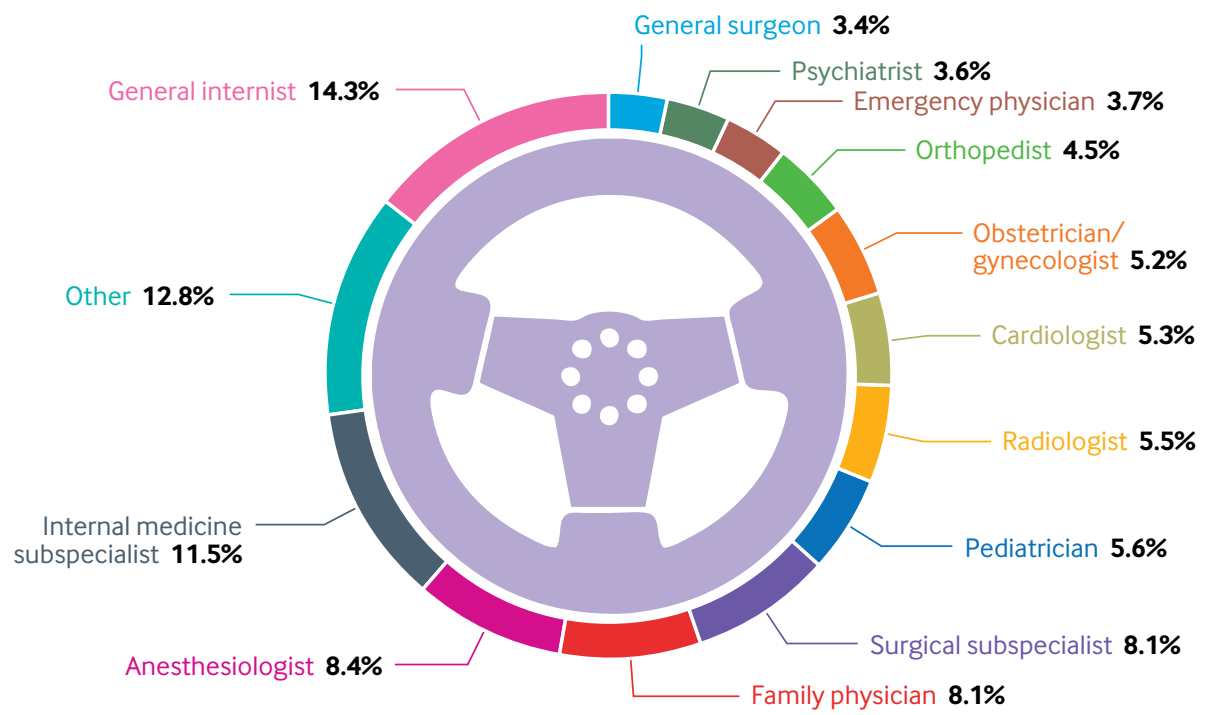

Fig 2 | Distribution of 2915 tickets for speeding by specialty to physicians driving luxury cars

speeding tickets in the general population is supported by publicly available insurance industry studies.

Across the distribution of registered speeds over the limit, peaks at $5 \mathrm{mph}$ intervals probably relate to rounding, with the notable exceptions of $6 \mathrm{mph}$ above the speed limit-the minimum speed for which a ticket will be given-and a noticeable increase at $9 \mathrm{mph}$ that strongly suggests speed discounting. We hypothesized that certain specialties may be treated more leniently by police officers than others, independent of factors such as physician age and sex that are correlated with specialty choice. For example, police officers could, in theory, show preference toward emergency medicine providers or surgeons since these specialties are often involved in the care of police officers who are injured while on duty. Moreover, police officers routinely accompany individuals who have been arrested or are incarcerated and require urgent medical care, further increasing interaction with emergency department physicians. Despite these hypotheses, we found no relation between physician specialty and leniency by police officers when issuing tickets for speeding. Moreover, physicians and non-physicians experienced similar leniency by police officers, which suggests officers might not be aware of the driver's profession or may lack any preference toward physicians. However, other traits, such as female sex and older age, were independently associated with leniency.

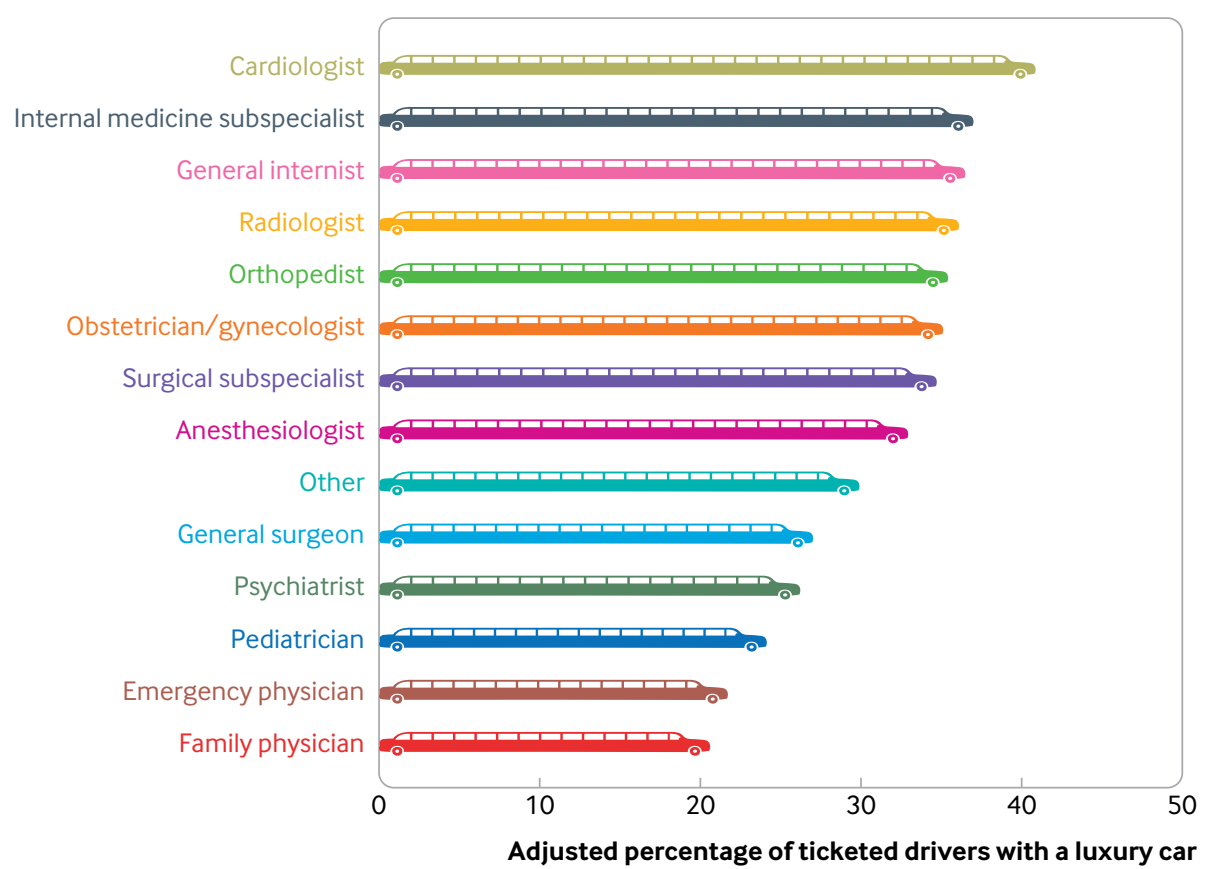

Fig 3 | Adjusted percentage of physicians ticketed for speeding while driving a luxury car by specialty. Percentages were adjusted for age and sex 


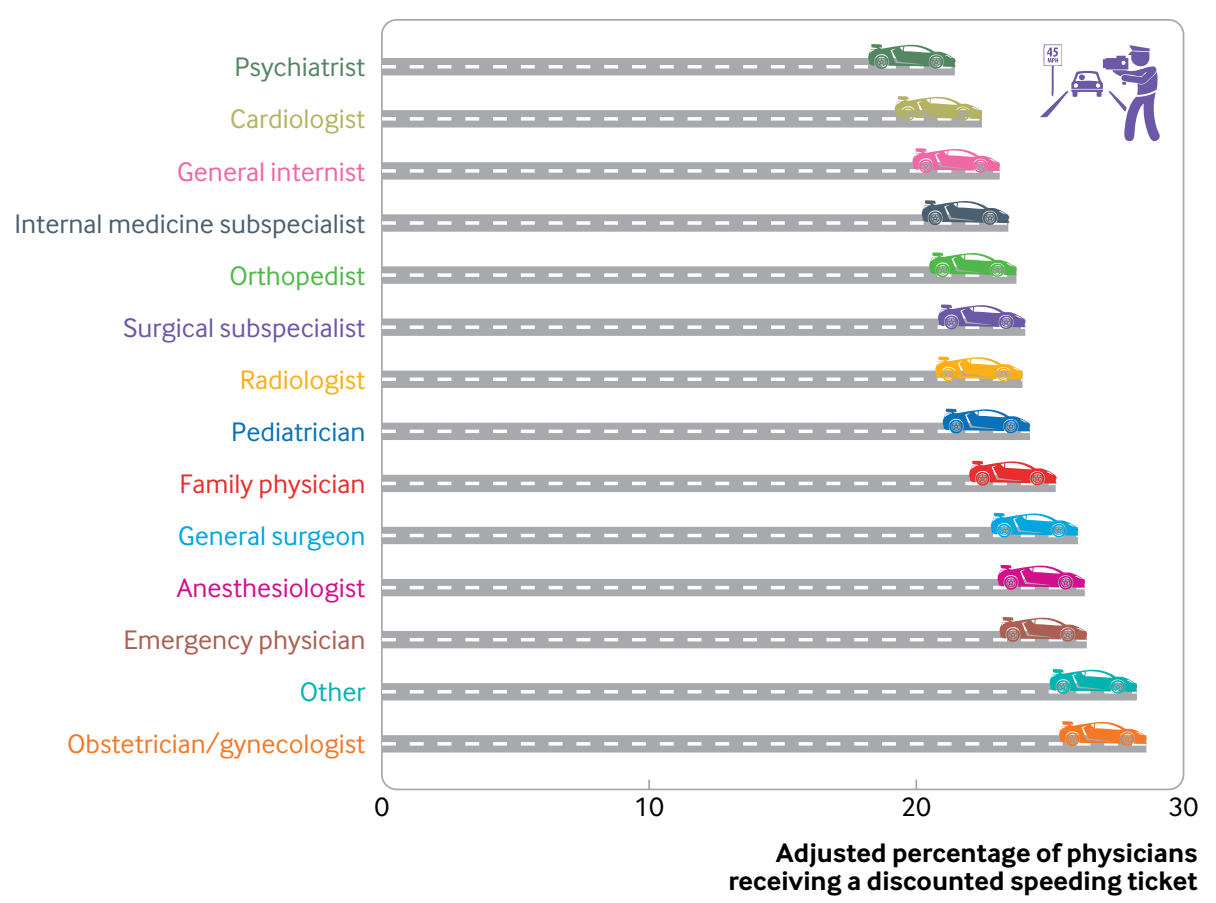

Fig 4 | Leniency by officers toward physicians pulled over for speeding, by specialty. Percentages were adjusted for age and sex

\section{Limitations of this study}

Our study has several limitations. First, our sample included physicians who received tickets for speeding in Florida, and therefore results might not be generalizable to areas with different driving cultures, demographics, or policing practices. Second, although mismatches are possible between databases, it is unclear why these would be systematically different between physician specialties in a way that would lead to bias in estimates of the outcomes that we studied. Third, make of car and speed were not registered in many tickets, but it is also unclear how this would introduce bias toward specialties. Fourth, though we adjusted for factors such as age and sex that are correlated with choice of specialty, other unobserved factors might also be correlated with the choice and the outcomes that we studied. Fifth, our sample did not include verbal or written warnings from police officers, which could represent an important, unmeasured form of leniency. Sixth, our analyses were based on physicians who received speeding tickets; it is possible that the distribution of extreme speeding and of luxury car ownership across all physicians, ticketed or not ticketed, might differ. An analysis of this sort would require information on the denominator of physicians in each specialty as well as information on average miles driven in each specialty.

\section{Conclusions}

In a large sample of speeding tickets issued to physicians in Florida, extreme speeding was common among physicians who received a ticket, and although rates of extreme speeding were broadly similar across physician specialties and between physicians and non-physicians, rates of extreme speeding were higher among ticketed psychiatrists. Differences in luxury car ownership among physicians who received a ticket for speeding were significant, with ticketed cardiologists most likely to drive a luxury car. The connection between the driving behavior of physicians and patient outcomes remains unknown.

Contributors: All authors contributed to the design and conduct of the study, data collection and management, analysis and interpretation of the data, and preparation, review, or approval of the manuscript. ABJ supervised the study and is the guarantor. The corresponding author attests that all listed authors meet authorship criteria and that no others meeting the criteria have been omitted.

Funding: $A B$ J is supported by grants from the Office of the Director, National Institutes of Health (NIH Early Independence Award, grant 1DP50D017897)

Competing interests: All authors have completed the ICMJE uniform disclosure form at www.icmje.org/coi_disclosure.pdf and declare: no financial relationships with any organizations that might have an interest in the submitted work in the previous 3 years; and no other relationships or activities that could appear to have influenced the submitted work. ABJ reports having received consulting fees outside this work from Pfizer, Bristol Myers Squibb, Novartis, Amgen, Eli Lilly, Vertex Pharmaceuticals, AstraZeneca, Celgene, Tesaro, Sanofi Aventis, Biogen, Precision Health Economics, and Analysis Group. The research conducted was independent of any involvement from the sponsors of the study. Study sponsors were not involved in study design, data interpretation, writing, or the decision to submit the article for publication.

Ethical approval: The data were obtained from publicly available data sources and were exempt from human subjects' review.

Data sharing: No additional data available.

$\mathrm{ABJ}$ affirms that the manuscript is an honest, accurate, and transparent account of the study being reported; that no important aspects of the study have been omitted; and that any discrepancies are disclosed.

This is an Open Access article distributed in accordance with the Creative Commons Attribution Non Commercial (CC BY-NC 4.0) license, which permits others to distribute, remix, adapt, build upon this work non-commercially, and license their derivative works on different 
terms, provided the original work is properly cited and the use is noncommercial. See: http://creativecommons.org/licenses/by-nc/4.0/.

1 Davis E, Whyde A, Langton L. Contacts between police and the public, 2015. Bureau of Justice Statistics, United States Department of Justice 2018. www.bjs.gov/content/pub/pdf/cpp15.pdf.

2 Zhang G, Yau KK, Chen G. Risk factors associated with traffic violations and accident severity in China. Accid Anal Prev 2013;59:18-25. doi:10.1016/j.aap.2013.05.004

3 Burns PC, Wilde G. Risk taking in male taxi drivers: Relationships among personality, observational data and driver records. Pers Individ Dif 1995:18:267-78. doi:10.1016/0191 8869(94)00150-Q

4 Jena AB, Sunstein C, Hicks T. The benefits of having the same name as a police officer. New York Times 2018, April 4.
5 Goncalves F, Mello S. A few bad apples? Racial bias in policing. In: Princeton University working paper; 2017.

6 Anbarci N, Lee J. Detecting racial bias in speed discounting: Evidence from speeding tickets in Boston. Int Rev Law Econ 2014;38:11-24. doi:10.1016/j.irle.2014.02.002

7 Koplewitz G, Blumenthal DM, Gross N, Hicks T, Jena AB. Golf habits among physicians and surgeons: observational cohort study. BMJ 2018;363:k4859. doi:10.1136/bmj.k4859

8 Cooke Fl, Richards DB, Kellett CF, et al. Bangers and cash: multicentre survey of what doctors are driving. BMJ 1999;319:1616-17. doi:10.1136/bmj.319.7225.1616

Supplementary information: list of luxury car makes and additional figures and tables 